\title{
Sonolytic Desorption of Mercury from Aluminum Oxide: Effects of pH, Chloride and Organic Matter
}

Ziqi He, Samuel J. Traina, and Linda K. Weavers

\section{Supporting Information \\ 1 Table, 1 Page}

Table S1. Characteristics of Pahokee peat humic acid

\begin{tabular}{c|c|c|c|c}
\hline $\begin{array}{c}\text { Aromaticity } \\
(\%)\end{array}$ & $\begin{array}{c}\text { SUVA } \\
(\text { at } 254 \mathrm{~nm}) \\
\left(\mathrm{m}^{-1} \mathrm{~L} / \mathrm{mgC}\right)\end{array}$ & $\begin{array}{c}\text { Carboxyl } \\
\text { content } \\
(\mathrm{meq} / \mathrm{g} \text { TOC })\end{array}$ & $\begin{array}{c}\text { Weight-averaged } \\
\text { molecular weight } \\
(\mathrm{Da})\end{array}$ & $\begin{array}{c}\text { Number-averaged } \\
\text { molecular weight } \\
\text { (Da) }\end{array}$ \\
\hline 39.4 & 5.56 & 4.27 & 4200 & 2500 \\
\hline
\end{tabular}

